\title{
Periabutment soft tissue outcomes following single-stage bone anchored hearing device implantation with tissue preservation at a tertiary referral centre.
}

Kanzara T, Walijee H, Sheikh R, Temple R.
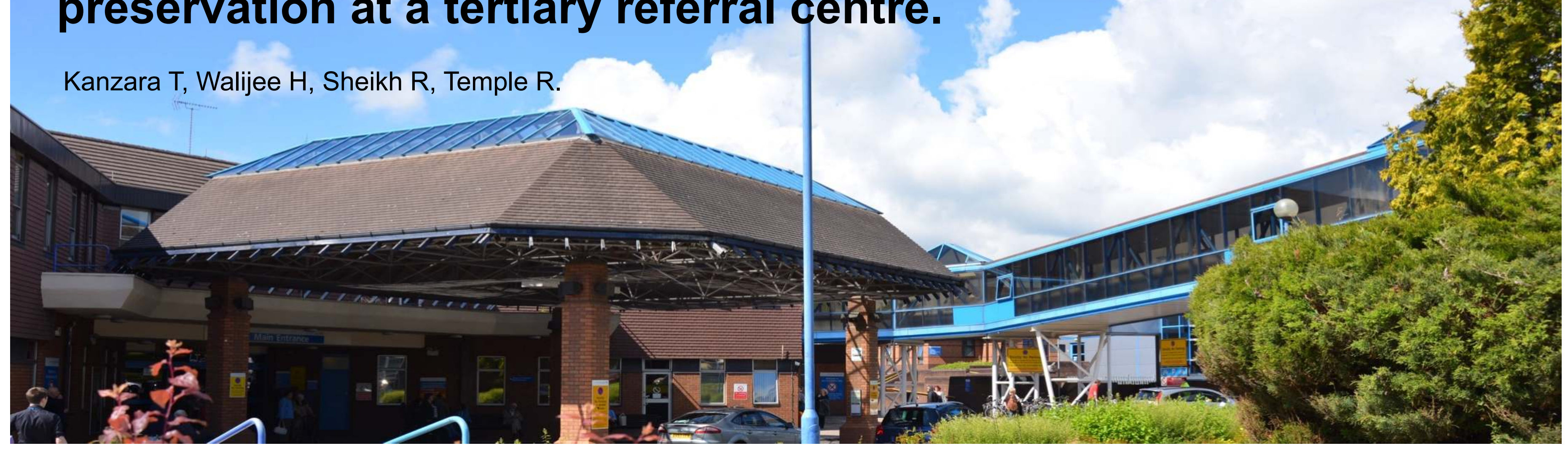

\section{Conclusion}

In our experience the tissue preservation technique is the procedure of choice for bone anchored implant surgery. The tissue preservation technique minimises patient morbidity, is possible with local anaesthesia and bear excellent soft tissue outcomes.

\section{Aim}

To investigate skin-related post-operative complications following a tissue preservation technique in percutaneous hydroxyapatite-coated concave bone anchored hearing aid (BAHA) implantation.

\section{Method}

A retrospective review of adult patients who underwent single-stage osseointegrated hearing aids insertion between July 2013 and November 2017 at our institution was carried out. The senior author (RT) performed all the procedures using a soft-tissue preservation technique described in Wilkie et al 2014. Patients were reviewed in the outpatient department at 1 week, 4 weeks, 3 months, 6 months and annually post operatively and soft tissue reactions were graded by Holger's classification.

\section{Results}

102 patients were included with a slight female preponderance (female:male 56:46). At 1 week postimplantation, 94 patients $(92.2 \%)$ had a Holger 0. At 4 weeks, 15 patients $(14.7 \%)$ scored $\leq 2$ and 5 patients $(4.9 \%) \geq 3$. At 3 months, 11 patients $(10.7 \%)$ scored $\leq 2$ and 3 patients $(2.9 \%) \geq 3$. At 6 months, 11 patients $(10.7 \%)$ scored $\leq 2$ and 2 patients $(1.9 \%) \geq 3$. 3 patients required removal of the BAHA abutment due to persistent soft tissue reaction on average 15.6 months post-implantation. 2 patients had the BAHA re-implanted due to traumatic dislodgement. The average follow-up period for our cohort was 8.5 months (SD 8.3 months).

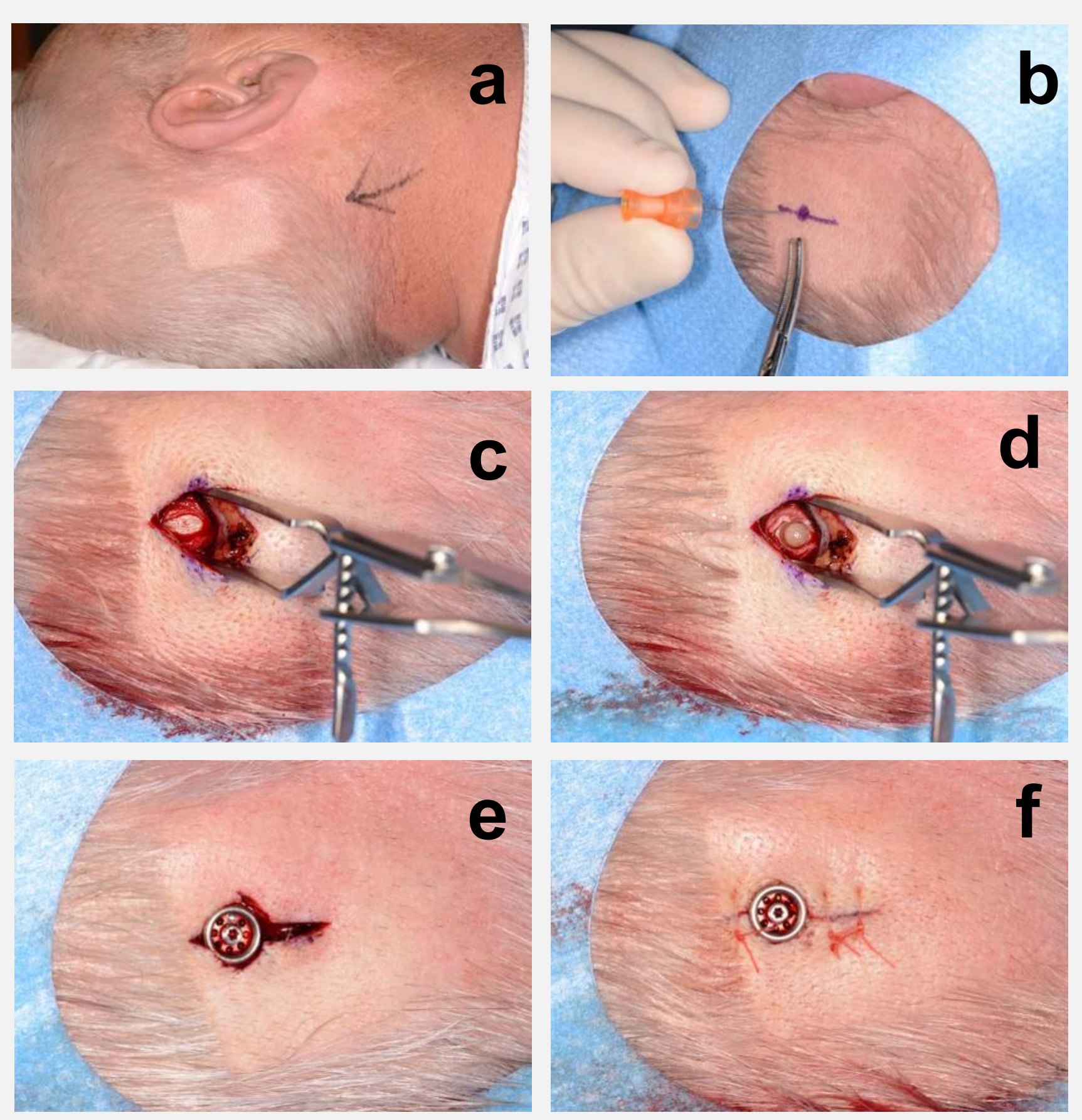

Figure:

a- patient supine, with implantation site shaved.

b- scalp thickness measured with $25 \mathrm{~g}$ needle prior to local anasethetic infiltration

c- horizontal incision through the periosteum

d- drill down to $4 \mathrm{~mm}$ depth with drill guide and widen with countersink at 2000rpm

e- implant in place. A small triangle of skin excised from either side of the implant to aid closure

f- interrupted skin closure with absorbable suture material.
Countess of Chester Hospital Hussein Walijee

ENT Registrar • Department of Otolaryngology

Liverpool Road, CH2 1UL, Chester

\section{Reference}

Wilkie M, Chakravarthy K, Mamais C, Temple R. Osseointegrated hearing implant surgery using a novel hydroxyapetite-coated concave abutment design. Otolaryngol Head Neck Surg 2014 Sepr 22
Countess of Chester Hospital NHS Foundation Trust 